\title{
The ecological impact of conquest and colonization on a medieval frontier landscape: combined palynological and geochemical analysis of lake sediments from Radzyń Chełminski, northern Poland
}

\section{Article}

Published Version

Creative Commons: Attribution 3.0 (CC-BY)

Open Access

Brown, A., Banerjea, R., Dawn-Wynne, A., Stivrins, N., Jarzebowski, M., Shillito, L.-M. and Pluskowski, A. (2015) The ecological impact of conquest and colonization on a medieval frontier landscape: combined palynological and geochemical analysis of lake sediments from Radzyń Chełminski, northern Poland. Geoarchaeology, 30 (6). pp. 511-527. ISSN 08836353 doi: https://doi.org/10.1002/gea.21525 Available at https://centaur.reading.ac.uk/39714/

It is advisable to refer to the publisher's version if you intend to cite from the work. See Guidance on citing.

To link to this article DOI: http://dx.doi.org/10.1002/gea.21525

Publisher: Wiley

All outputs in CentAUR are protected by Intellectual Property Rights law, including copyright law. Copyright and IPR is retained by the creators or other copyright holders. Terms and conditions for use of this material are defined in 
the End User Agreement.

www.reading.ac.uk/centaur

\section{CentAUR}

Central Archive at the University of Reading

Reading's research outputs online 


\title{
The Elements of Well-Being
}

BRAD HOOKER

University of Reading

\begin{abstract}
This essay contends that the constitutive elements of well-being are plural, partly objective, and separable. The essay argues that these elements are pleasure, friendship, significant achievement, important knowledge, and autonomy, but not either the appreciation of beauty or the living of a morally good life. The essay goes on to attack the view that elements of well-being must be combined in order for well-being to be enhanced. The final section argues against the view that, because anything important to say about well-being could be reduced to assertions about these separable elements, the concept of well-being or personal good is ultimately unimportant.
\end{abstract}

\section{CLARIFICATIONS}

Like most philosophers, I will take the term 'well-being' to be synonymous with 'welfare', 'personal good', and 'individual utility'. Contributions to well-being I refer to as benefits or gains. Subtractions from well-being I refer to as harms, losses, or costs. The elements of well-being are whatever constitutes benefits, that is, contributions to well-being.

Absolutely essential is the distinction between non-instrumental value, which is sometimes called final value, and instrumental value. Examples of things with merely instrumental value are money, medicine, and sleep. This paper focuses on non-instrumental value. When I refer to contributions to well-being, I mean non-instrumental contributions, that is, things that are good for us in their own right as opposed to good only because they are means to other things. The main focus of the paper is on 
the question of what constitutes non-instrumental contributions to a person's wellbeing. Definitely, all of the values I will be discussing do have instrumental value. But I will be focusing on these values not for their instrumental benefits but as putative elements of well-being.

\section{HEDONISM}

Hedonism is the theory that well-being consists in pleasures minus pains. Pleasures are experiences found attractive solely because of their experiential quality, rather than for other reasons. Pains are experiences found aversive solely because of their experiential quality, rather than for other reasons. ${ }^{\text {. }}$

The focus on experiential quality brings out a defining feature of pleasures and pains, namely that they are introspectively discernible (which is not to say that they are actually discerned). Imagine someone who fails in the central project of her life but never finds out about this failure. An example might be the amateur sleuth who spent the last five years of her life trying to discover how and why the child Madeleine McCann disappeared. The sleuth died thinking that she had made the crucial discovery that solved the case. But in fact her 'discovery' turned out to be quite mistaken. Because she didn't find out that she failed, her pleasures were what they would have been had her project instead been a success. Hedonists hold that the failure of a life project does not, in itself, reduce the person's welfare. Hedonists think that a person's welfare is determined solely by how this person's life feels from the inside. How her life feels from the inside may depend in part on whether she believes her desires have been fulfilled. How her life feels from the inside does not necessarily depend on whether her desires really have been fulfilled. (For recent defences of hedonism, see Feldman, 2004, and Crisp, 2006, ch. 4.)

I have contended that introspective discernibility is essential to pleasure and that success in one's projects is not. This is true whether the project is relatively discrete, such as finding out how and why a small child suddenly disappeared, or much more complex and general, such as the goals of having lots of good friends and of being knowledgeable about science, history, and metaphysics and of creating things of enduring value. Consider someone who believes that he has enough good friends and that he is knowledgeable about science, history, and metaphysics and that he has

I. Here I am especially grateful to anonymous reviewers for wording. 
created things of enduring value. This person is likely to feel some satisfaction with his life.

Perhaps this sort of satisfaction is the most important kind of pleasure (Sumner, I996, ch. 6). Nevertheless, getting this kind of pleasure is possible even if one is deluded about whether one's desires for good friends, for knowledge of science, history, and metaphysics, and for creative success have actually been fulfilled. Feeling satisfied with one's life is compatible with delusion about pretty much everything except whether one feels satisfied with one's life.

\section{DESIRE-FULFILMENT}

Another main view of welfare holds that a person's well-being is constituted by the fulfilment of his or her desires, whether or not the person knows the desires have been fulfilled. This view is often called the desire-fulfilment (or preference-satisfaction) theory of well-being.

The main argument in favour of the desire-fulfilment theory over hedonism is that many people's self-interested concern extends beyond their own pleasures and pains, enjoyments and frustrations (Nozick, I974, esp. p. 43). For example, many people have stronger self-interested concern for knowing the truth (especially about whether their other desires are fulfilled) than for blissful ignorance.

The main argument against the desire-fulfilment theory is that some desires are so wacky that their fulfilment would not itself constitute a benefit for the people who have them (even if whatever associated pleasure these people derived from believing their desires were fulfilled would constitute a benefit for them). Imagine someone who wants a saucer of mud, or to count all the blades of grass in the lawns along a street, or to turn on as many radios as possible (Anscombe, I958, p. 70; Rawls, I97I, p. 432; Quinn I993, p. 236). Suppose this person wants these things for their own sakes, i.e., non-instrumentally. Fulfilment of such desires in itself would not be of any benefit to this person, we intuitively think.

\section{OBJECTIVE LIST THEORY}

A third theory of welfare agrees with hedonism that pleasure constitutes a benefit. Where this third theory departs from hedonism is over the question of whether there is only one element of well-being or more than one. The third theory 
claims that other things can also constitute benefits-for example, knowledge of important matters, friendship, significant achievement, and autonomy. Derek Parfit (1984, pp. 493-502) dubbed this theory the 'objective list theory', but often the name is shortened to the 'list theory'. According to this objective list theory, a life contains more welfare to the extent that it contains pleasure, knowledge of important matters, friendship, significant achievement, and autonomy. A life full of pleasure and fulfilment of desires for things other than the goods just listed could still be of low quality precisely because it lacked the goods just listed. (For discussion, see Griffin, I986, pp. 29-35, 58-72; Crisp, 1997, ch. 3.)

What makes one achievement more significant than another? Thomas Hurka (I993, chs. 8-IO; 20II, ch. 5) argues persuasively that extended and difficult achievements are more significant than narrow and easy ones. Admittedly, a narrower and less difficult achievement might benefit you more than one that is more extended and difficult, because the narrower one brings you greater pleasure or because it helps develop your friendships or because you learn more from it. In other words, when instrumental as well as intrinsic value is considered, a narrower and less difficult achievement can be on balance more beneficial to you than a wider and more diffcult achievement. But when we ignore the instrumental benefits of different achievements, we should conclude that extended and difficult achievements are more significant than narrow and easy ones.

We might likewise follow Hurka (I993, chs. 8-IO; 20II, ch. 4) in holding that extended and explanatory knowledge is better than narrow and shallow knowledge. For example, knowledge of the basic truths of physics or biology or metaphysics is more important than knowledge of the batting averages achieved by the middle-ranking players on a particular team in a particular month thirty-three years ago. But knowledge about yourself or things closely connected to you can sometimes constitute a larger benefit to you than would more general knowledge about things with no special connection to you. Knowing important facts about yourself-having self-knowledge-is a more important element of your well-being than knowing general truths about physics or biology or metaphysics or other people. For example, knowing your own failings is more important than knowing other people's failings. On the other hand, knowing that something is true not only of you but also of everyone else would constitute a larger benefit than knowing merely the truth about yourself.

Even more contestable than which kind of achievement or knowledge is most valuable as an element of well-being is the question of exactly what comprises auton- 
omy. Does autonomy consist merely in having one's actions be guided by desires that one desires to have? Or does autonomy consist in having one's decisions be guided by one's own value judgements? Or does autonomy require that one's value judgements be themselves autonomously produced? Or does autonomy require that one's value judgements be at least minimally sensible?

These questions are fascinating but, alas, too difficult to address here. Hence, I must simply assume an answer. This is that someone's life contains autonomy to the extent to which she has a variety of important options to choose among, her choices reflect her value judgements, and her value judgements are at least minimally reflective (i.e., she has at least once considered them rather than merely always accepted them without consideration). If Jack severely constricted Jill's set of important options, or if he controlled her choices by controlling her value judgements, she would lack autonomy. The same would be true if a brain injury or mental illness controlled her value judgements or prevented her from being able to assess them.

Now, how can we ascertain whether any given putative good is an item on the objective list? We must run the following kind of thought experiment. We imagine two possible lives for someone that are as much alike as possible except that one of these lives contains more of some candidate good than the other. We then think about whether the life containing more of the candidate good would be more beneficial to the person living it than the other life. If the correct answer is no, then definitely the candidate good in question is not an element of well-being. On the other hand, if the correct answer is instead that the life with more of the candidate good is more beneficial, then we inquire what is the right explanation of this life's being more beneficial. One possible explanation is that the candidate good in question really is an element of well-being.

\section{PLEASURE}

Here is an illustrative example. We imagine two possible lives for someone that are as much alike as possible except that one of these lives contains a larger amount of innocent pleasure than the other. We are trying to hold everything equal as much as possible with the single variable being the amount of innocent pleasure in the two possible lives. We then think about whether the life containing the larger amount of innocent pleasure would be more beneficial to the person living it than would be the as similar as possible life with a smaller amount of innocent pleasure. If the correct 
answer is that the life containing the larger amount of innocent pleasure would not be more beneficial to the person living it than would be the as similar as possible life with a smaller amount of innocent pleasure, then innocent pleasure is not an element of well-being. On the other hand, if the correct answer is that the life with a larger amount of innocent pleasure is more beneficial, then we need to inquire what is the right explanation of this life's being more beneficial. The explanation that suggests itself is that innocent pleasure is indeed an element of well-being.

For that possible explanation to be correct, rival possible explanations must be mistaken. Perhaps the leading rival possible explanation is that, although by hypothesis the two lives being compared are as much alike as possible with the exception that one includes a larger amount of innocent pleasure than the other, the fact that one of these possible lives contains a larger amount of innocent pleasure brings with it differences in the levels of other goods and these differences are what account for the superiority of one possible life to the other. In short, although our thought experiment was supposed to isolate one variable, the rival possible explanation claims that other variables are not only ineliminable but also pivotal.

Here is an example of such a rival explanation. This explanation begins with the proposal that the life with the larger amount of innocent pleasure must also have contained a larger amount of significant achievement or friendship or important knowledge or autonomy, as sources of the extra innocent pleasure. This rival explanation then adds that what makes the life with the larger amount of innocent pleasure more beneficial to the person who lives it than the life with a smaller amount of innocent pleasure is not the extra innocent pleasure but instead the larger amount of significant achievement or friendship or important knowledge or autonomy.

This rival explanation starts from a false supposition-namely, that the life with the larger amount of innocent pleasure must also have contained a larger amount of significant achievement or friendship or important knowledge or autonomy, as sources of the extra innocent pleasure. This supposition is false because the extra pleasure might have come from insignificant achievement or unimportant knowledge or false beliefs or the satisfaction of physiological urges. The source of innocent pleasure can be trivial or misconceived or merely physiological. There is no necessity that source of innocent pleasure is itself something valuable, much less an element of well-being.

We can conclude, then, that innocent pleasure is definitely an element of wellbeing. This is the best explanation of why a life containing a larger amount of in- 
nocent pleasure would be more beneficial to the person living it than another possible life as much as possible like the first one except that this life contains a smaller amount of innocent pleasure.

I am aware that, to many people, the thesis that innocent pleasure is an element of well-being seems completely obvious. However, there are some people who do not find innocent pleasure obviously valuable. My argument above is aimed at these people. Later in this essay, there is an argument aimed at people who think innocent pleasure is valuable only if obtained in the course of a worthwhile activity.

\section{SIGNIFICANT ACHIEVEMENT}

The structure of the argument above can be applied to other candidate elements of well-being. Let us apply it to significant achievement. We imagine two possible lives for someone that are as much alike as possible except that one of these lives contains a larger amount of significant achievement than the other. We are trying to hold everything equal as much as possible with the single variable being the amount of significant achievement in the two possible lives. We then think about whether the life containing the larger amount of significant achievement would be more beneficial to the person living it than the life that contains a smaller amount of significant achievement but is otherwise as similar as possible. If the correct answer is no, then significant achievement is not an element of well-being. However, the correct answer seems to me to be that the life with a larger amount of significant achievement is more beneficial to the person who leads that life than the life that contains a smaller amount of significant achievement but is otherwise as similar as possible.

Now, what is the best explanation of this life's being more beneficial? One possible explanation is that significant achievement is indeed an element of well-being. The rival possible explanation starts from the supposition that the life with the larger amount of significant achievement must also have contained a larger amount of innocent pleasure or friendship or important knowledge or autonomy. From this supposition, the rival explanation infers that what makes the life with the larger amount of significant achievement more beneficial to the person who lives it is not the extra significant achievement but instead the larger amount of pleasure or friendship or important knowledge or autonomy.

Lives containing a larger amount of significant achievements often do also have more pleasure, friendship, important knowledge, or autonomy in them than they 
would have had if they had contained a smaller amount of significant achievement. But this certainly is not always true. Sometimes people sacrifice pleasure, friendship, and important knowledge for the sake of pursing significant achievement. Indeed, obsession about a goal can be instrumental to achieving it but at the same time in conflict with obtaining pleasure, alienating to friends and potential friends, and a blinker to information not relevant to the goal. For such reasons, there is no necessity that a larger amount of significant achievement correlates perfectly with a larger amount of pleasure, friendship, or important knowledge. This is especially obvious in cases where the person who made a significant achievement never found out about it, and thus could not have gained lots of pleasure from knowing about the achievement.

So what is the correct explanation of the fact that the life containing the larger amount of significant achievement would be more beneficial to the person living it than the life that is as similar as possible except that it contains a smaller amount of significant achievement? The correct explanation cannot be that the life with the larger amount of significant achievement must also have contained a larger amount of innocent pleasure or friendship or important knowledge or autonomy. The correct explanation is instead that significant achievement is an element of well-being.

\section{IMPORTANT KNOWLEDGE}

The same kind of argument can be run for concluding that important knowledge is an element of well-being. Imagine that two lives are as much alike as possible except that one of those lives has important knowledge and the other life does not or one life contains a considerably larger amount of important knowledge than the other. The life containing no or a considerably smaller amount of important knowledge is worse for the agent than a life as much as possible like that one except that it contains at least some or a considerably larger amount of important knowledge.

Again, we have to ask, what is the best explanation of the greater benefit in the life with a larger amount of important knowledge? One possible explanation is that important knowledge is indeed an element of well-being. The rival possible explanation starts from the supposition that the life with the larger amount of important knowledge must also have contained a larger amount of innocent pleasure or more friendship or a larger amount of significant achievement or greater autonomy. From this supposition, the rival explanation infers that what makes the life with the larger amount of important knowledge more beneficial to the person who lives it is not the 
extra important knowledge but instead the greater pleasure or friendship or significant achievement or autonomy.

We should not accept the supposition that the life with the larger amount of important knowledge must also have contained a larger amount of innocent pleasure or friendship or significant achievement or autonomy. Sometimes important knowledge reduces rather than increases innocent pleasure. Sometimes important knowledge harms friendships. Sometimes important knowledge is not a significant achievement because it was not something that was pursued and thus not an achievement at all. Hence the life with the larger amount of important knowledge might not also contain greater innocent pleasure or friendship or significant achievement or autonomy.

Thus, the best explanation of the fact that a life containing no or a considerably smaller amount of important knowledge is worse for the agent than a life as much as possible like that one except that it contains a larger amount of important knowledge cannot be that the life with the larger amount of important knowledge must also contain greater innocent pleasure or friendship or significant achievement or autonomy. The best explanation must instead be that important knowledge is an element of well-being.

\section{AUTONOMY}

Concerning autonomy, we can try an argument with the same structure as the arguments above. We imagine two possible lives for someone as similar as possible except that one contains more autonomy and the other less. Then we ask which of these two possible lives is more beneficial to the person who lives it. The autonomous life seems better. Since we have imagined that the two lives are as equal as possible in terms of the other elements of well-being, we minimize the extent to which the superiority of the more autonomous life can be explained by the instrumental value of autonomy.

Again, we face the objection that there are multiple, though correlative, variables here. The objection is that, if one possible life contains greater autonomy than another possible life that is otherwise as similar as possible, the possible life with greater autonomy in it must also contain greater pleasure or knowledge or friendship or achievement than the other life. From this supposition, the objection infers that the greater pleasure or knowledge or friendship or achievement, and not the greater autonomy, is what makes this life better. 
However, it just is not true that if one possible life contains greater autonomy than another life that is otherwise as similar as possible, then the possible life with greater autonomy in it must also contain greater pleasure or knowledge or friendship or achievement. Greater autonomy might lead to some successes but also, of course, to some failures-some missed opportunities for pleasure, some lack of knowledge, some ruined friendships, and some unsuccessful projects. So, on balance, greater autonomy might not lead to greater pleasure or knowledge or friendship or achievement. So there is nothing to prevent our imagining two possible lives that are equal in terms of pleasure, friendship, achievement, and knowledge and yet one of these lives contains more autonomy than the other.

We thus ask which of these two possible lives is more beneficial to the person who lives it. The more autonomous life seems better. Since we have imagined that the two lives are as equal as possible in terms of the other elements of well-being, the best explanation of the superiority of the more autonomous life in this comparison is that autonomy is an element of well-being.

\section{APPRECIATING BEAUTY}

Experiencing something as beautiful can definitely be instrumental to other benefits. Most obviously, experiencing something as beautiful can produce pleasure, even ecstasy. Experiencing something as beautiful can also lead to other goods, such as love and knowledge. But is experiencing something as beautiful a non-instrumental good such that a life containing such appreciation must be pro tanto better than a life without?

Well, are judgements of beauty like judgements of taste, i.e., merely subjective? Whether a food is delicious or not is merely subjective. For example, if you judge pears to be delicious and I do not, neither of us need be mistaken. If beauty is like deliciousness, then while you can be correct about whether you find something's aesthetic qualities attractive, you cannot be correct about whether these qualities really are attractive or about whether they ought to attract. If beauty is like deliciousness, then what would make a possible life in which you find more beauty better for you than a possible life in which you find less beauty would be the additional pleasure or friendship that the extra beauty would bring you. If beauty is like deliciousness, then appreciating beauty is not itself an element of well-being.

If beauty is not like deliciousness but is instead an objective value, then you can 
be correct not merely about whether certain qualities attract you and others but also about whether certain qualities really are attractive or about whether they ought to attract. In that case, you can have knowledge of aesthetic properties. If this is correct, perhaps we should classify appreciation of beauty as a kind of important knowledge. If appreciation of beauty is a kind of important knowledge, then we have grounds for holding that appreciation of beauty is an element of well-being-under the heading of important knowledge.

\section{LIVING A MORALLY GOOD LIFE}

Let us now turn to the question of whether living a morally good life is an element of well-being. Even if it is not, living a morally good life is of course morally good. And living a morally good life might be what there is strongest reason to do even where living a morally good life involves self-sacrifice. We can be interested in the question of whether living a morally good life is an element of well-being even if we are committed to sacrificing our own good either for the sake of benefiting others or because moral restrictions get in the way of doing what is most beneficial to oneself.

Living a morally good life is rewarding in terms of the other elements of well-being. Living a morally good life definitely constitutes a significant achievement. ${ }^{2}$ And living a morally good life can bring pleasure and ferment friendship. And knowing what morality requires is important knowledge. But is living a morally good life in itself-not under the heading of achievement, or as an instrument to pleasure or friendship, or in its connection with knowledge-an element of well-being?

This is not a question to which the answer seems to me directly apparent. The best I can do is approach the question indirectly, via what I call the sympathy test (I first proposed this test in Hooker, I996, pp. I49-53).

Suppose we ask ourselves whether we are inclined to feel sympathy for someone whose life lacks a particular property. Sympathy is a judgement-sensitive attitude (on judgement-sensitive attitudes, see Scanlon, I998, pp. 20-22). Our having sympathy for someone whose life lacks a particular property makes sense only if we judge that a life's lacking that property makes the life less beneficial to the person whose life it is than would be a life as similar as possible except that it has this property. So if we

2. An anonymous reviewer suggested that living a morally good life might not be much of an achievement if the agent were surrounded by people who always provided incentives for acting morally. That such incentives are always provided seems to me unrealistic. 
do feel sympathy for someone whose life lacks the property, this attitude makes sense only if deep down we think that a life's having that property is an element of wellbeing. And if we do not feel sympathy for someone whose life lacks the property, one possible explanation is that deep down we think that a life's having that property is not an element of well-being.

We do feel sympathy for people whose lives lack pleasure, friendships, autonomy, significant achievement, or important knowledge without some sort of compensation in terms of a greater amount of one or more of these other goods. In contrast, we do not feel sympathy for people who fail to live morally good lives. One possible explanation of the absence of sympathy is that deep down we really do not believe that living a morally good life is an element of well-being.

Is the sympathy test a good one? If we do have sympathy for someone, we can legitimately make inferences about our beliefs. To be more specific, if we do feel sympathy for someone whose life lacks a particular property, then we must think that a life's lacking this property makes the life less beneficial to the person whose life it is than would be a life as similar as possible except that it has this property. The limitation of the sympathy test appears in cases where we do not feel sympathy for someone whose life lacks a particular property. Yes, one possible explanation for our lack of sympathy is that we really think that a life's having that property is not an element of well-being. However, another possible explanation is that something else prevents us from feeling sympathy. For example, we might think that the person under consideration deserves a life with lower well-being.

We might initially suspect that feeling sympathy for someone is difficult to combine with the condemnation and blame and indignation that we feel towards those we believe have failed to lead morally good lives. Moral blame is regularly accompanied by a kind of hostility, which can get in the way of sympathy.

And yet, blaming someone does not necessarily get in the way of feeling sympathy for that person. Sometimes we have to blame someone about whom we care very strongly. When we blame someone about whom we care very strongly, the blame can be accompanied by sympathy. For example, we might blame ourselves for something but at the same time feel sorry for the harm we have caused to ourselves. ${ }^{3}$

So far in this argument I have assumed that we do not feel sympathy for people who fail to live morally good lives. I have cast suspicion on the attempt to explain this lack of sympathy as an effect of blame for those who fail to live morally good lives.

3. I am grateful to Penelope Mackie for pointing this out to me. 
Blame for people who fail to live morally good lives does not always prevent sympathy for them. So I tentatively surmise that the best explanation of our lack of sympathy for people who fail to lead morally good lives is that we do not really think that living such a life is a distinct element of well-being. (This conclusion should be tempered by the recognition that living a morally good life can be instrumentally beneficial to the person who lives it and can constitute a significant achievement.)

\section{FOR WELL-BEING, FRIENDSHIP IS MORE THAN A KIND OF ACHIEVEMENT}

Earlier, I argued that friendship should be listed as a distinct element of wellbeing. I have just now appealed to the sympathy test to argue that we do not really believe that living a morally good life is a distinct element of well-being, though living a morally good life is a kind of significant achievement, which is an element of wellbeing. With that conclusion in mind, someone might appeal to the fact that forming and sustaining friendships is also an important kind of achievement, albeit one less multi-dimensional than living a morally good life.

I do not see how it could plausibly be denied that that forming and sustaining friendships is also an important kind of achievement. Here is an example. Imagine someone named Frieda who has found the good in a friend named Markus and forgiven him and sustained her interest in him for decades. This really is an impressive achievement on her part, given how conflicted and moody and self-deluded and intermittently self-destructive Markus is. (In contrast, that he has continued to love her is no achievement on his part, given how breathtakingly easy she is to admire and appreciate.)

Now consider the following argument:

Premise I: Forming and sustaining friendships is like living a morally good life in being an important kind of achievement.

Premise 2: Living a moral life is not a distinct element of well-being.

Premise 3: If forming and sustaining friendships is like living a morally good life in being an important kind of achievement, and if living a morally good life is not 
a distinct element of well-being, then forming and sustaining friendships is not a distinct element of well-being.

Conclusion: Forming and sustaining friendships is not a distinct element of well-being.

Since this argument's conclusion does follow from the premises, we should assess the premises. Premise $\mathrm{I}$ is clearly true. Premise 2 is the conclusion we reached via application of the sympathy test, and so let us accept this premise. Premise 3 presumes that different things that are alike in one relevant respect are also alike in other relevant respects. We should not accept this premise, since different things are sometimes not alike in more than one relevant respect. Rejecting premise 3 , we must reject the above argument as unsound.

To show that an argument is unsound is not to show that its conclusion is false. In the case of the above argument, however, I think there is an argument showing that its conclusion is false. In other words, this is an argument to show that forming and sustaining friendships is in fact a distinct element of well-being.

This argument begins with the premise that there is diminishing marginal benefit in each element of well-being (this argument was inspired by Hurka, 1993, pp. 84-96; 20II, pp. I66-74). For example, a life with no achievement but a lot of pleasure would benefit a great deal from gaining a significant achievement. Let us dub this achievement $\mathrm{A}$ of size S. Compare a very different life, one with lots of achievement already. This second life would not benefit as much from gaining the same achievement $\mathrm{A}$ of the same size S. In other words, the two lives we are comparing each gain an achievement $A$ of size $S$; but, in the life where this is the only significant achievement, achievement A of size S constitutes a large benefit, and, in the life where there were already lots of other achievements, achievement A of size $S$ constitutes a smaller benefit.

The diminishing marginal benefit to a life of its containing more instances of a kind of value of which it already contains a lot is relevant for the following reason. Imagine a life that already contained a lot of achievement but as yet no friendship. Suppose now this life gains one friendship. If friendship were not a distinct element of well-being but instead merely a subcategory of achievement, then a life that already contained a lot of achievement but as yet no friendship would not benefit much from the addition of one friendship. However, a life that already had a lot of achievement 
but as yet no friendship would benefit hugely from the addition of one friendship. So friendship is not merely a subcategory of achievement but instead is a distinct element of well-being.

\section{SEPARABLE-ELEMENT-VS-COMBINED-ELEMENT THEORIES}

Let us turn from the question on what is on the list of elements of well-being to the question of whether the elements must be combined or need not be combined. We can agree that the very best life is one containing all the elements listed-pleasure, knowledge of important matters, friendship, significant achievement, and autonomy. Now we can distinguish between two kinds of objective list theory. These two kinds disagree about whether each of knowledge of important matters or friendship or significant achievement or autonomy on its own constitutes a benefit. CombinedElement Theories hold that only in combination do the listed items constitute benefits. Separable-Element Theories hold that the listed elements constitute benefits to the agent even when the agent does not have the other items. For example, on the Separable-Element Theory, knowledge of important matters (or significant achievement) constitutes a benefit to the agent even if it produces no pleasure for the agent.

Joseph Raz offers a particularly influential version of the Combined-Element view. Raz champions the partly objectivist view that well-being consists in the successful pursuit of worthwhile goals-in a slogan, 'subjective engagement with objective value'.

Raz's theory is partly objectivist because which goals are worthwhile is an objective evaluative question about values. '[G] oals are supported by approving judgement. ... [O]ne must regard one's goals in a way which ascribes to them desirability characteristics.' (Raz, I986, p. 300) People 'engage in what they do because they believe it to be a valuable, worthwhile activity. ... To the extent that their valuation is misguided it affects the success of their life.' (Raz, I986, p. 299) '[A] person's belief that his goal is valuable does not make it so.' (Raz, I986, p. 344) People can think they are pursuing goals with desirability characteristics and yet be mistaken. People can unknowingly pursue valueless goals. And people who are successful in pursuing valueless goals do not thereby add to their well-being, according to Raz.

Raz's theory is not wholly objectivist. Facts about the individual subject's intentions and psychological engagement matter crucially. In Raz's view, someone would 
fail to benefit from having good things in her life like knowledge and friendship if she did not have the right intentions and attitudes towards these things.

I agree with Raz that the kind of life that is best for any agent is one full of the successful pursuit of valuable goals. Furthermore, his ranking of active over passive states seems right. However, in contrast with Raz, I contend that pleasure can add to an agent's well-being even if this pleasure is not associated with the successful pursuit of worthwhile goals.

Suppose Ajay has a life with a given amount of successful pursuit of worthwhile goals. (For the purposes of my argument, it doesn't matter whether this amount is high, or low.) Now suppose that Ajay is given an increment of passive pleasure, not pleasure from the pursuit of worthwhile goals. Maybe he is introduced to a drink he can savour each night right before bed. Or perhaps he is blessed with particularly pleasurable dreams each night. In either case, hasn't his well-being increased, admittedly only a little, but still increased? I propose that, of any two individuals with equally successful pursuit of equally worthwhile goals, the one whose life contained more pleasure, even if this pleasure is only of a passive kind, has had greater well-being.

Raz anticipated this objection (I995, p. 7):

Not all pleasures contribute to one's well-being. ... I stretch myself on the beach and enjoy the warmth of the sun; I see a pretty rose, and enjoy the sight. My life is not better or more successful as a result. It is different if I am a beach bum, or ... a flower lover. But in that case the passive pleasure fits in with my activities, I am the sort of person who will make sure that there is room in his life for these pleasures. In that case the occasional pleasure contributes (if it does) to my well-being because it contributes (a tiny bit) towards the success of activities I am set upon. If I have no interest in sun on the beach or in flowers, these pleasures, while being real enough and while valuable as pleasures, do not contribute to my well-being. They have no bearing on my life as a whole. ... [T]he pleasure has a meaning in the life of the flower lover which differs from its meaning in the life of the one who is not. That difference makes it reasonable to regard the pleasure as active in one case and passive in the other. It is active where it meshes with one's general orientation in life.

Of course I agree that pleasures matter more to some people than they do to others. And I agree that the pleasure of looking at a flower differs in meaning depending on whether that pleasure meshes with one's projects. But agreeing with Raz about 
those matters does not preclude thinking that passive pleasures do add to well-being, even if less than active pleasures. Examples such as the one about Ajay suggest that passive pleasures do add to well-being. (That said, perhaps passive pleasures of the kind Raz is discounting are lexically inferior to goods of other kinds. What I mean is that no amount of these passive pleasures is large enough to be worth choosing over a significant amount of those other goods. For discussion, see Crisp, 1996, pp. 23-42.) Hence, I am willing to be a bit more subjectivist than Raz.

I am also willing to be a bit more objectivist than Raz. Suppose someone stumbles upon some important wisdom or 'falls into' a rewarding relationship. Even if obtaining important wisdom and having rewarding relationships were not this person's goals, do not the wisdom and the relationship this person obtains add to her well-being? Suppose now that she does not appreciate the value of that wisdom or relationship until very late in life. That the value was not appreciated earlier is sad. But when finally it is appreciated, the thought that our agent might have would be 'here has been this good in my life all along and I didn't realize it. Because of this good in my life, I was better off than I thought.'

Such thoughts are possibly correct. And when they are correct, their correctness does not depend on the agent's having them. Put crudely, it could be a true proposition that, because of a great unappreciated good pervading the person's life, this person had been better off than she realized. The truth of this proposition does not depend on the person's ever coming to believe the proposition. In other words, if the person dies without having ever even considered the proposition, the proposition might nevertheless be true. But if this proposition is true, then an agent's subjective appreciation of a good is not a necessary condition of that good's adding to her well-being.

Raz himself denies what he calls the 'transparency of intrinsic value', that is the thesis that 'a feature is intrinsically good only if, under normal conditions, the person (or other animal) for whom it is a good is content with its presence and prefers it to its absence'. (Raz, I986, p. 269; cf. pp. 268, 32I) I too deny the transparency of intrinsic value. Because I deny this transparency, I can hold that a person's well-being was greater because of some wisdom she happened upon or a relationship she fell into, although, throughout the time her life contained these elements, she was not content with their presence and did prefer their absence.

Again, Raz anticipated the idea. He wrote (I995, p. 6), 
The condition of whole-hearted pursuit presupposes that even where the activity, commitment, or relationship is not one which the agent chose, or could abandon by choice, he is in control of the manner of his engagement in it. He has to direct his conduct in the light of his objectives and commitments, to guide himself towards his goal. ... In the main, the notions involved ... exclude resentment, pathological selfdoubt, lack of self-esteem, self-hate, etc. One is acting whole-heartedly if one is not prey to one of these attitudes. Nothing else is required: no reflective endorsement of one's activity, no second-order desire to continue with it, etc.... The fact that certain alternatives never cross one's mind may be a condition of having an appropriate attitude to people or activities.

The concession Raz makes here is compelling. In order for an activity to benefit the person who engages in it, it is not necessary for the person to reflectively endorse the activity or to have a second-order desire to desire it. Where the agent's activity or relationship or other good is something he does not reject or resent, his successful engagement with it adds to his well-being.

Nevertheless, Raz's concession does not, I think, go far enough. His 'condition of whole-hearted pursuit' restricts the activities and relationships that constitute benefits to an agent to those activities and relationships that the agent does not doubt, reject, or resent. However, an agent's activity or relationship or some other good in his life could be something that he actively rejects or resents and yet this activity or relationship or some other good in his life could still constitute an addition to his well-being. Of course, the upset he experiences is a loss for him. But the loss should not blind us to the possible associated gain.

For illustration, imagine an agent who has a relationship that she did not choose but came to resent, and this resentment went on for years. But then finally she came to see that in fact this relationship was a blessing she hadn't recognized. Though not chosen, and long resented, this relationship, she discovers, turns out to be one of the most significant things in her life. Perhaps it turns out to be the only significant relationship in her life, maybe even the only significant good in her life. Neither the fact that she didn't choose the relationship nor the fact that she resented it for years precludes the relationship's constituting an important addition to her well-being.

Again, this is a truth that the agent might come to see. Then again, the agent might not be so fortunate as to come to see it. The agent's recognition of the truth 
would be very good. However, this recognition isn't a necessary condition of the truth's obtaining.

I have contended that the limits of well-being extend farther both in a subjectivist direction and in an objectivist direction than Raz allows. I have argued that passive sensations (a subjective element) can be sufficient on their own to constitute at least a little well-being. I have also argued that objective goods such as knowledge and relationships, even if not chosen and even if resented, can on their own constitute an addition to well-being, though the distress they cause also constitutes a subtraction from well-being. Whether the addition is greater than the subtraction depends on the importance of the knowledge, the nature of the relationship, and the amount of distress. Perhaps it also depends on how much other knowledge the person has, and on how many other relationships her life contains.

To reiterate, the greatest well-being is constituted by whole-hearted, successful pursuit of worthwhile goals. What Raz has described-the combination of subjective and objective elements-is the ideal. But the separate elements constitute some benefit even when not combined with the others.

\section{THE IMPORTANCE OF THE CONCEPT OF WELL-BEING}

Once we analyze well-being into its elements, we encounter a challenge to the importance of the concept of well-being. The challenge is that, since anything important to say about well-being could be reduced to assertions about these elements, we can jettison the concept of well-being. ${ }^{4}$ The challenge is to explain why the concept of well-being is not at best otiose. I will argue that it is not otiose.

Let us distinguish between intrapersonal trade-offs and interpersonal ones. In an intrapersonal trade-off, a loss in terms of a person's well-being occurs for the sake of a greater gain in terms of that same person's well-being. In an interpersonal trade-off, a loss in terms of one person's well-being occurs for the sake of a benefit to someone else.

In both intrapersonal cases and interpersonal trade-offs, there is difference between cases where gains and losses being traded off are in terms of a single element of well-being and cases where the gains and losses being traded off involve multiple elements of well-being. An example of an intrapersonal case involving a single element

4. This challenge was put to me at a conference on Happiness and Well-Being in Oxford in June 2013 . 
is my agreeing to take on some pain now for the sake of my having much less pain in the future than I would have if I did not take on the pain now. An example of an interpersonal case involving multiple elements is my taking some pain now for the sake of protecting your autonomy or your pursuit of significant achievements or your knowledge or your friendships.

In thinking about gains and losses involving multiple elements, we rightly find thinking in terms of well-being irresistible. The reason for this is, again, that significant achievement, important knowledge, friendship, autonomy, and pleasure have diminishing marginal value within a life.

Imagine that you could give your niece enough money for a very pleasant week at the beach. Alternatively, you could give your nephew enough money to enable him to delay for a week going back to his paid employment, and this week of free time would enable him to complete his musical score. Should you just weigh the amount of pleasure your niece would get against the magnitude of the achievement constituted by your nephew's completed score?

No, you should instead think about the size of the benefit your niece would get out of that quantity of pleasure and the size of the benefit your nephew would get out of his artistic achievement. And the sizes of the benefits to the different people of the pleasure and achievement would depend upon how much other pleasure your niece's life contains or how much other achievement is in your nephew's life. What matters really are the sizes of the benefits, not purely the quantities of pleasure and significant achievement taken on their own. In other words, what matters is the size of the additions to each's well-being, not the quantities of the elements added to each.

Acknowledgements: For helpful comments on an earlier version of this paper, I take pleasure in thanking Krister Bykfist, Roger Crisp, Tom Hurka, Eden Lin, Ingmar Persson, Julian Savulescu, Anthony Skelton, Valerie Tiberius, and two anonymous reviewers for this journal.

\section{REFERENCES}

Anscombe, E. I958. Intention, Oxford, Blackwell Publishers

Crisp, R. 1997. Mill on Utilitarianism, London, Routledge.

2006. Reasons and the Good, Oxford, Clarendon Press.

Feldman, F. 2004. Pleasure and the Good Life, Oxford, Clarendon Press. 
Griffin, J. 1986. Well-Being, Oxford, Clarendon Press.

Hooker, B. 1996, 'Does Moral Virtue Constitute a Benefit to the Agent?' In R. Crisp, ed., How Should One Live?, Clarendon Press, I4I-55.

Hurka, T. 1993. Perfectionism, Oxford, Clarendon Press.

20II. The Best Things in Life. Oxford: Oxford University Press.

Nozick, R. 1974. Anarchy, State and Utopia, Oxford, Blackwell Publishers.

Parfit, D. 1984. Reasons and Persons, Oxford, Clarendon Press.

Quinn, W. 1993. Morality and Action, Cambridge, Cambridge University Press.

Rawls, J. 1971. A Theory of Justice, Cambridge, MA, Harvard University Press.

$\mathrm{Raz}$, J. 1986. The Morality of Freedom, Oxford, Clarendon Press.

-1995. 'Duties of Well-Being', in Raz, Ethics in the Public Domain, Oxford, Clarendon Press.

Scanlon, T. 1998, What We Owe To Each Other, Cambridge, MA, Harvard University Press, 1998.

Sumner, L. W. 1996, Welfare, Happiness, and Ethics, Oxford: Clarendon Press. 